\title{
NOTAS SOBRE O RETORNO DO TEOLÓGICO-POLÍTICO
}

Otávio Velho ${ }^{1}$

\author{
${ }^{1}$ Programa de Pós-Graduação em Antropologia Social, Museu Nacional, \\ Universidade Federal do Rio de Janeiro, Brasil
}

Os cientistas sociais são levados a buscar regularidades na vida social movidos pelos ossos do seu ofício. E os conceitos utilizados orientam e refletem essa prática. Por isso mesmo, costumam ter dificuldade em lidar com eventos insólitos do ponto de vista das expectativas de regularidade estabelecidas, o que acaba por aproximá-los dos leigos na matéria, reduzindo assim o privilégio de um saber específico. São expectativas alimentadas em geral por valores e pressupostos não questionados na pesquisa empírica normal ou, mesmo, que não têm presença reconhecida; quanto mais não seja em sua profundidade. Como a crença moderna em uma evolução social unilinear, teleológica e, por princípio, eurocêntrica, que foi intelectualmente hegemônica até recentemente tendo como marco original a obra de Hegel (1770-1831). E a cuja influência estamos, ainda, sujeitos por ter sido transformada em imaginário do senso comum, conduzindo assim à convicção subsequente no desaparecimento inelutável, definitivo e progressista do que são consideradas peias do passado. Convicção que, por sua vez e por via de suas variantes, atravessa o espectro político-ideológico, dadas a intensidade e a multiplicidade dos afetos que a reproduzem.

É o que ocorria com a suposição de que tenderíamos a uma convergência racial no Brasil e a um embranquecimento gradativo da população, o que norteou gerações de expertos e não deixou de pagar um tributo à eugenia pelo qual a ciência ainda está por se penitenciar. Ou é também o que ocorre com a suposição segundo a qual as sociedades indígenas estariam fadadas 
ao desaparecimento ou à assimilação. São, ambas, exemplos de posturas cuja perda de dominância relativa revela o quanto foram e são dependentes da correlação de forças sociais e políticas - questão a que voltaremos - e o papel que indubitavelmente desempenham os movimentos sociais nessa perda. Assim como também são revelados os movimentos reativos e por vezes de bloqueio à nova conjunção, que tendem a perdurar e a aguçar-se ao se confrontarem com o que é percebido como ameaças insólitas a um padrão de dominação estabelecido.

No que diz respeito à religião, de certa forma ocorre, ao invés de uma aproximação, um distanciamento dos cientistas sociais - e dos acadêmicos de uma forma mais geral - em relação à maior parte da sociedade, constituindo-se como que um senso comum distinto, erudito. Isto porque em um país onde as "religiões" são largamente praticadas, não só entre os intelectuais prevalece o contrário, como prevalece-inclusive como mecanismo de reforço - a aposta no seu desaparecimento ou em sua restrição ao espaço privado, o que se reflete inclusive em um interesse tardio e limitado por seu estudo. Um exemplo eloquente em função de sua área de trabalho, mas longe de único, é o de Chauí, que em um de seus diversos e importantes livros sobre o filósofo Espinosa diz que "a superstição religiosa e a tirania teológica de que fala [Espinosa] são próprias do século XVII" (Chauí 2001:82). E que as nossas formas de alienação contemporâneas, ao invés, têm origem na mídia, na imprensa, na escola e na propaganda. Já há certo lapso de tempo desde a publicação desse livro e, à época, esta era a visão - não exclusiva, como veremos - predominante, o que sem dúvida dá o que pensar, não apenas no que diz respeito ao objeto da afirmação, mas como revelador de um padrão de pensamento mais geral em que não só transparece o unilinearismo subjacente, mas também a tendência a supor a extensão congelada no tempo de uma determinada constelação de forças que caracterizaria necessariamente a modernidade.

Mas ainda quanto à religião - e sem querer exagerar as identidades disciplinares - nesse particular parece haver um diferencial no caso dos antropólogos; embora não menos sujeitos às afetações do entorno, sem dúvida prevalece aí uma relativização da unilinearidade. Relativização esta que se manifesta na afirmação da presença religiosa, na da importância do ponto de vista dos crentes em contraste com os oficialismos e na diversidade desse campo. É de se registrar que essa diversidade era afiançada pelos antropólogos desde há algumas décadas; desde o tempo em que prevalecia a assertiva de que não só o país, mas também o conjunto da nossa região - afora a suposta excepcionalidade uruguaia - seriam arraigadamente católicos e como que fadados ao catolicismo. 
Vista retrospectivamente, a aposta na diversidade parece ter representado um raro momento de prospecção baseada em indícios que só o trabalho etnográfico apurado ou a vivência pessoal poderia ter fornecido. Todavia, se posicionarmos o caso brasileiro em um contexto global, talvez sejamos levados a considerar essa diversidade como relativamente tímida quando confrontada com outras regiões do mundo. Mesmo porque fenômenos como as várias manifestações de New Age ou de neo-ayahuasqueiros que se deram entre nós diversificaram-se internamente, mas se mantiveram restritos a nichos que não continuaram a se expandir do modo que aparentavam poder fazer há algumas décadas atrás, mesmo porque, normalmente, não cultivam o proselitismo.

Nossa diversidade religiosa se restringiu basicamente ao âmbito do cristianismo, no qual, aí sim, a expansão evangélica com suas derivações pentecostais de fato contrapôs-se eficazmente à hegemonia católica, até mesmo ao expô-la, embora a marcação da importância do ponto de vista dos crentes em contraposição aos oficialismos sugira ainda a existência de diversidades e agrupações no interior desse universo, supridoras de apoios e serviços informais os mais variados e pouco visíveis ao conjunto da sociedade (Reis 2021).Mas visíveis em seus efeitos, tal como registrados na constatação, apoiada em sondagem, segundo a qual a percentagem de brasileiros que leva em conta a opinião de seus líderes religiosos quando do ato de votar é amplamente minoritária: 19\% segundo pesquisa Datafolha de 2017, subindo moderadamente para $26 \%$ entre evangélicos, sugerindo a existência de outras instâncias de afetação em presença dentro do mesmo universo.

Por outro lado, a própria natureza dessa diversidade revela-se insólita em relação às expectativas. Supunha-se em geral - e se apostava - tratar-se de uma diversidade benigna. Suposição que em certos casos não deixava de guardar um parentesco com o diálogo inter-religioso de origem eclesial por efeito de incorporação e mesclagem com interlocutores eruditos. Mas pelo contrário, essa diversidade - e há certa dose de autocrítica nesta constatação - veio em alguns casos a alcançar tal ponto em matéria de agressividade que paradoxalmente hoje dá sinais de que de fato possa vir a restringi-la. Sobretudo no caso-limite da demonização das religiosidades de matriz africana, em que se chega a atos de guerra, religiosa e de narrativas, mas não só (Velho 2017a). O quadro, portanto, mostra-se mais contraditório do que se poderia supor anteriormente. 
Recuando para o século XVII: o Tratado Teológico-Político do filósofo Baruch de Espinosa (1632-77) é um texto entre cujos atributos estava o de ser originalmente um manifesto. Uma peça de resistência, embora sutil, o que não o livrou dos rumores maledicentes e da proibição de circulação da sua obra. Resistência em defesa da tolerância religiosa e da liberdade de expressão que até certo ponto distinguiam a república holandesa - ou, mais amplamente, as Províncias Unidas - no contexto europeu, apesar do domínio oligárquico, do colonialismo e da presença proeminente da Casa de Orange-Nassau. República atravessada por divisões internas e conflitos que acabariam por destruí-la e na qual as múltiplas denominações e seitas protestantes com suas polêmicas teológicas e demonizações se imiscuíam nas disputas políticas, sobretudo através dos pastores calvinistas. Além de manifesto, o TTP é também considerado um trabalho pioneiro de hermenêutica bíblica, tendo sido acompanhado de um compêndio de gramática da língua hebraica que restou inacabado. Mas também aí havia o propósito político circunstancial de reduzir o espaço para as especulações teológicas dos pastores ao estabelecer o que está efetivamente dito na Bíblia e que poderia, portanto, ser consensualmente aceito sem conflitos, esperava o autor (Velho 2020).

Porém estes relevantes episódios estão longe de esgotar o significado do livro. No que diz respeito à relação entre religião e poder, Aurélio já havia afirmado sobre ele (Aurélio 2000) - em contraste com a posição contemporânea de Chauí - e reiterado de forma sintética posteriormente,

Que o texto continua vivo, ninguém, decerto, o negará, perante o lastro de 'teológico-político' que de novo assoma hoje à superfície da modernidade, tão enfaticamente inaugurada, no que à política diz respeito, por Espinosa, lastro esse que no seu recorrente emergir, a confronta com o seu próprio negativo e exibe à transparência a imbricação de poder e sagrado, sobre cuja denúncia e recalcamento ela se construiu e mantém. ... Se, de fato, pelo menos no Ocidente e desde há dois séculos, recusamos esse cruzamento do poder e da religião, que transfigura a lei em mandamento e o discurso político em teologia, é principalmente porque Espinosa, como alguém já disse, se nos antecipou a ir espreitar por detrás do espelho, a indagar a natureza da imagem que qualquer sociedade tem de si própria, e da sua lei ou ordem interna, concluindo que ela não é senão isso mesmo, ou seja, uma simples imagem, que a perspectiva irremediavelmente particular de cada um e de cada povo tende a representar como espaço onde a transcendência irrompe, soberana, de modo a que a potência do legislador se cubra de legitimidade inquestionável (Aurélio 2019:9-10). 
E que:

Imaginar o Tratado Teológico-Político confinado à circunstância específica e, em muitos aspectos, absolutamente ímpar da Holanda do século XVII, sem olhar ao que nessa obra se nos impõe como elemento matricial da política quando pensada à luz da liberdade individual, é passar simultaneamente ao lado do texto de Espinosa e do que realmente constitui a modernidade em política (Aurélio 2019:10).

Em geral, o que fizeram os pensadores da modernidade ao apartar-se da tradição foi deslocar a política para o terreno da racionalidade. Como o fez o filósofo Thomas Hobbes (1588-1679) paradigmaticamente ao centrar-se no "contrato" e numa cesura profunda com o chamado "estado de natureza". Daí o deslocamento também para o terreno do insólito de tudo o que pudesse contradizer este passo fundador. O que distinguiu Espinosa foi retirar do sagrado a supremacia ontológica, mas reconhecendo a sua permanência como resíduo de natureza imaginária, mas performativo e, portanto, impossível de ser eliminado. Mesmo tendo perdido a prerrogativa de fundamento natural do poder, e mesmo quando se trate de uma presença não reconhecida como tal, pois representa uma contradição inerente à modernidade de cuja necessidade o pensamento político moderno em suas diversas modalidades não costuma se dar conta. É o caso usual da sacralização do poder em questões como a da sua legitimidade, do povo enquanto sujeito, da soberania, da hierarquia, da organização social e de sua ritualística de símbolos e performances, pois a estabilidade traduz "um equilíbrio que é necessário renovar permanentemente" (Aurélio 2011:21). Paradoxo de uma racionalidade que não se basta e que precisa em sua essencialidade mesma recorrer ao seu negativo.

Mas a possibilidade de retorno deste negativo assumido efetivamente enquanto tal fica, então, igualmente inscrita nessa concepção espinosana. Mais do que retorno, talvez se trate, pois, de uma explicitação de presença, o que leva a um descolamento, que pode ocorrer, por exemplo, numa crise do imaginário subsumido no poder, já que:

[...] jamais os homens renunciaram ao seu próprio direito e transferiram para outrem a sua potência em termos tais que deixassem de ser temidos pelos que receberam deles o direito e a potência, e que o Estado não estivesse mais ameaçado pelos cidadãos, ainda que privados do seu direito, do que pelos inimigos (Espinosa 2019:335). 
A questão é de afetos. E por isso de imagens e de quebra de imagens. E não há contrato ou pacto que se superponha à descoberta de que o rei está nu, pois a política é feita com a natureza dos homens tal qual é e com a potência da multidão em sua inconstância como causa imanente do direito comum, refletindo-se sob a forma da ordem jurídica (Aurélio 2011:57).

III

Atualmente tem sido repetido com insistência que estamos diante de uma crise das instituições e, particularmente, das instituições que dizem respeito à democracia representativa. Mas como dizia Espinosa, os homens jamais renunciam em definitivo à sua potência, o que pode se refletir numa desconfiança em relação à política e aos políticos - e ao próprio Estado que não é tão insólita quanto se afigura confrontada com a letra da lei. E mais uma vez um ponto crítico parece ter sido alcançado atualmente, e não só entre nós.

Essa desconfiança da política e a rejeição ao Estado não é desconhecida na história dos últimos séculos. Deixando de lado as manifestações do imaginário popular (Velho 2007), basta recordar o movimento anarquista, grande antagonista do marxismo-leninismo e da ditadura do proletariado que pretenderia colocar o Estado a serviço de uma nova classe, a qual, no entanto, mesmo aí, segundo a doutrina, deveria eventualmente abolir o Estado, uma vez cumprida a sua missão teleológica.

Mais recentemente, a propensão à desconfiança e/ou rejeição do Estado ganhou novos representantes vindos desta vez do Sul global em nome do combate ao eurocentrismo, que teria dominado a vida social, política e intelectual nos últimos séculos, como que coincidindo com a própria formação dos Estados nacionais (Velho 2017b). E como parte dessa tendência, desenvolveu-se uma vertente latino-americana - sobretudo andina, mas de ampla circulação - tendo como marco a obra do sociólogo peruano Aníbal Quijano (2014) e a valorização da presença dos povos indígenas. Valorização esta reavivada como afirmação da possibilidade de modos de vida alternativos e da reconciliação das sociedades humanas com a natureza. Sem entrar no mérito da obra de Quijano e outros intelectuais da mesma estirpe no seu conjunto, pode-se dizer que essa valorização, tal como protagonizada pelos movimentos sociais, representaria um confronto direto com a teleologia unilinear dominante. E aqui, o grande antagonista é justamente um representante maior dessa teleologia: o "desenvolvimentismo", aparentemente imbatível dadas, aqui também, 
a variedade e a multiplicidade dos afetos que o constituem. Ocorre, no entanto, que esse embate nos últimos anos tem sido sobredeterminado por sua vez pelo reconhecimento crescentemente consensual - não mais restrito aos movimentos ecológicos pioneiros - de estarmos envolvidos por alterações climáticas de proporções sem precedente em milhares de anos. Alterações desta vez de origem antrópica e que nos mergulham no que Ailton Krenak já apelidou de abismo cognitivo, obrigando o desenvolvimentismo até então triunfante como telos a se qualificar como "sustentável", o que produz uma clivagem no interior dessa dominância que complexifica o embate, não mais reduzido a dois antagonistas em situação de assimetria.

Por outro lado, o termo desenvolvimento continua também a ser utilizado de modo indeterminado, o que permite mal-entendidos produtivos na formação de acordos aparentes, necessários para a continuação dos jogos de linguagem dos relacionamentos políticos. Mesmo porque o desenvolvimento sustentável parece capturado por um dilema insolúvel entre a questão dos custos da energia a demandar o aumento da produção e as preocupações climáticas. Preocupações climáticas estas que entre nós ainda estão por se manifestar de modo eficaz, mas que criam uma pressão internacional cada vez mais intensa.

\section{IV}

Cabe notar que há muitas décadas a desconfiança e a rejeição ao sistema político e ao Estado costumavam emergir à esquerda no espectro político. Mais precisamente numa vertente minoritária da esquerda como vimos. Nos últimos anos, porém, deu-se uma migração expressiva para o polo oposto, o que levou muitos analistas e "formadores de opinião" a buscar analogias com fenômenos políticos das décadas de 20 e 30 do século passado (Velho 2019). Fato "insólito" a que se somou entre nós com força exponencial outro: a vitória dessa tendência nas eleições nacionais de 2018 com o tradicional tema da corrupção política como sua expressão primária. E com ela a possibilidade de implosão do sistema político a partir do seu interior por via de um personagem que tem sido identificado com o machadiano Simão Bacamarte. Identificação que ao contrário das representações correntes sugere certa recorrência de tal fenômeno com potencial de afetação e contágio.

Aqui não se pretende discutir esta história; mesmo porque as explicações históricas para o que se passa entre nós ainda têm de enfrentar o porquê das similitudes atuais com países de trajetórias muito diferentes, usualmente consideradas paradigmáticas. Como também não se pretende considerar 
essas aproximações possíveis com o que ocorre em outras partes do mundo. Porém pode ser interessante chamar a atenção para como, uma vez superado o fetiche do pacto, essa história pode de certa forma ser mais normalizada. E como, também, pode acenar na direção do rompimento com visões teleológicas. Tudo isso, no entanto, representando um desafio aos nossos hábitos intelectuais que não é pequeno.

Superado esse fetiche do pacto ou contrato, chega-se mesmo à possibilidade de aceitar em forma mais branda e qualificada algo que pode assim ser denominado; desde que se tenha em mente que a sua existência se dá somente enquanto perdurar determinada correlação de forças e com ela o direito e o poder do Estado. E onde "detém o máximo poder aquele que reina sobre os ânimos dos súditos", seja "levado pela esperança e pelo medo ao mesmo tempo, seja por reverência, que é uma paixão composta de medo e admiração, seja, enfim, por qualquer outro motivo" (Espinosa 2019:336).

Esse poder do Estado inclui necessariamente um sagrado embutido a que os cientistas políticos nem sempre dão atenção. E quando o Estado entra em crise, isto pode redundar num divórcio e numa erupção deste sagrado, as placas tectônicas, sempre em movimento, não o fazendo sem consequências quando existem falhas ou fraturas. Quando não as há, os grupos dominantes se acomodam entre si num novo arranjo, como ocorreu na nossa passagem da monarquia à república. Havendo erupção, porém, esta pode ser explosiva. Mas também pode ser efusiva, prolongando-se e, eventualmente, combinando-se com a outra possibilidade.

Como vimos, Chauí supunha que em nosso tempo o teológico-político seria substituído pela mídia, a imprensa, a escola e a propaganda. Mas ao que parece o sagrado hoje na verdade se manifesta justamente através desses meios, em proporções variáveis, a que poderiam ser acrescentadas outras, como as igrejas de cunho empresarial. Na verdade, o sagrado sempre assim se manifestou com a possível exceção deste último ponto; mas atualmente se dá uma exacerbação, juntamente com o avanço tecnológico, do mundo virtual, do mercado financeiro e dos modos de administração, exacerbação como efusão oriunda de uma perda de legitimidade do Estado e, por implicação, perda de sua sacralidade embutida e naturalizada. O "cruzamento do poder e da religião" a que se referiu Aurélio tenderia a um deslocamento em detrimento da lei e do discurso político e em benefício das religiões que, no entanto, em rebate, no caso presente seriam levadas paradoxalmente a assumir-se politicamente, pois ao demonizarem a política, na verdade emprestam-lhe o seu concurso. Uma nova sacralização surgiria então, carregando consigo, inclusive, agrupamentos religiosos e indivíduos cuja identidade fora definida por distanciamento em relação ao jogo político. 
Surgiria mesmo, numa reviravolta acrobática, em nível governamental, produzindo desde o seu interior uma espécie de magnicídio institucional em que a transfiguração havida do discurso político em teologia é agora como que invertida; embora a teologia não recupere com isso a sua supremacia ontológica anterior ao advento da modernidade. Essa transfiguração teológica no momento se torna pontualmente explícita na pauta de costumes. Mas também na linguagem de poder que uma liderança político-religiosaempresarial, sobretudo evangélica, emprestou ao negacionismo pandêmico (Guerreiro \& Almeida 2021).

E por que haveria essa perda (relativa) de legitimidade do Estado e de sua sacralidade? Por que a necessidade deste empréstimo, bem longe da autoimagem do moderno Estado laico? Como pressuposto, devido à sua instabilidade encoberta fragilmente pela imagem do contrato, e que lhe é intrínseca, e não devido à simples instrumentalização controlada. Tudo o que é sólido se desmancha no ar, conforme somos levados a perceber por eventos mundiais que colocam em dúvida solidezes consagradas e que se impunham como paradigmáticas. Os estereótipos se revelam como imagens e no ato se desvanecem.

Se é que se pode tirar alguma lição dessa mudança de perspectiva, há uma que os políticos bem conhecem. E que não é estranha aos motivos que levaram Espinosa a louvá-los de modo incomum logo no início do seu inacabado Tratado Político, no qual declara camonianamente, após afirmar que os filósofos creem "[...] fazer uma coisa divina e atingir o cume da sabedoria quando aprendem a louvar de múltiplos modos uma natureza humana que não existe em parte alguma" (Espinosa 2011:73), que, ao contrário do que se crê: "É no entanto inquestionável que os políticos escreveram sobre as coisas políticas de maneira muito mais feliz que os filósofos. Dado, com efeito, que tiveram a experiência por mestra, não ensinaram nada que se afastasse da prática" (Espinosa 2011:74).

Referimo-nos à necessidade de retirar as implicações advindas da inconstância da multidão e que se associam à instabilidade do Estado. Inconstância cuja origem está na combinação de vontades individuais com o jogo das afetações imitativas. Em uma multidão que para o político se apresenta nos tempos atuais primariamente como um "eleitorado"; e afetações que se manifestam por via das "nossas formas de alienação contemporâneas" a que se refere Chauí (2001:82).

É de se supor que o correspondente aos "filósofos" criticados por Espinosa - e há controvérsias sobre qual seria o alvo original dessa crítica espinosana - sejam entre outros aqueles que ignoram a inconstância da multidão e o poder dos afetos e do sagrado, embutido ou efusivo. 
Típica, então, é a crítica aos políticos por priorizarem as combinações eleitorais e o olhar nas pesquisas de opinião em detrimento das alianças político-ideológicas e a busca por afirmação de uma hegemonia moral e intelectual. Quando na verdade o pragmatismo político poderia ser considerado como uma homenagem à irredutibilidade da expressão da potência e aos afetos, a que o poder tem que se curvar. E o que faz a democracia - a mais natural das formas de governo nesse sentido - é liberar o confronto de perspectivas (imaginárias) sem privilegiar ou permitir imposições. E respeitando reviravoltas inesperadas, mas, nem por isso, arbitrárias.

Isto não significa que essas reviravoltas, por sua vez, sejam definitivas. Afinal, como já vimos, o poder eleitoral das lideranças religiosas, por exemplo, está longe de absoluto e, provavelmente, varia dentre essas lideranças a instância predominante em cada caso. Como não é de supor, por sua vez, que uma eventual nova volta no parafuso represente que, agora sim, as coisas retornam aos trilhos e devem prosseguir teleologicamente, milenaristicamente. Não só inexiste lei da história que o garanta, como também - do mesmo modo que se dá com as lideranças religiosas - as intelectualidades orgânicas em geral serão sempre minorias, cujo poder de mobilização imaginativa - de forma mimética ao que ocorre com o próprio Estado - não possui por detrás um contrato que lhes garanta fidelidades eternas. Os estadunidenses alcunharam a expressão "estados que flutuam" (swing states) para se referirem ao comportamento eleitoral de determinadas unidades da federação; mas a expressão poderia ter uso mais extenso.

\section{V}

Mas evidentemente a multidão não se restringe a seu atributo de eleitorado e nem ao espaço privilegiado dos políticos. E o que ocorre em outros espaços por vezes parece ir na contramão, escapando ao teológicopolítico. Tal como, quiçá, na questão do pertencimento identitário, cujas alterações e alargamentos - inclusive a discussão sobre a possibilidade de um novo momento, pós-identitário - em parte podem ser produto de uma dinâmica própria. Sempre, porém, correndo o risco de que - assim como já ocorreu com a diversidade religiosa - a afirmação identitária, ao invés de ter um sentido de celebração da diversidade, acabe por representar um encerramento nas semelhanças internas em proveito de seus representantes. Uma desafeição pelo conjunto da sociedade que dá pretexto a resistências. 
O retorno do teológico-político na modernidade é em boa medida um movimento de resistência. E sendo de natureza imaginária, não racional, a eliminação do teológico-político não é cogitável. A possibilidade desse retorno com presença própria e não somente como lastro de sacralidade subjacente estará, portanto, sempre posta. Resta, assim, buscar associar-se ao que poderíamos denominar um imaginário alegre, empotenciador (Velho 2020). As críticas ao progressismo latino-americano por vezes são indicadoras de um viés racionalista em que não há lugar para o imaginário. Por exemplo, ao se censurar uma solução política para os nossos impasses atuais por ser reveladora de um apego "messiânico" a um velho líder, quando a questão a ser posta, aí sim legitimamente, talvez devesse ser se essa identificação - necessariamente prenhe de inúmeras contradições - conduz no sentido de um aumento de potência coletivo ou não. Mas para isso seria preciso reconhecer que qualquer passo nessa direção será sempre relativo. E que supor o contrário é que nos manterá prisioneiros de uma teleologia de que o messianismo é uma versão teológico-política extrema.

* Agradeço a Diogo Pires Aurélio, Marcos Gleizer e Pedro Paulo Pereira pelo apoio de várias ordens na preparação deste texto.

Otávio Velho é Professor Emérito do Programa de Pós-Graduação em Antropologia Social do Museu Nacional da UFRJ, Membro-Titular da Academia Brasileira de Ciências, Presidente de Honra da Sociedade Brasileira para o Progresso da Ciência (SBPC).

http://orcid.org/0000-0001-5809-5354 


\section{Referências bibliográficas}

AURÉLIO, Diogo Pires. 2000. Imaginação e Poder. Lisboa: Edições Colibri. . "Introdução". 2011. In: Baruch de Espinosa, Tratado Político. Lisboa: Círculo de Leitores e Temas e Debates.

.2019. "Nota à terceira edição". In: Baruch de Espinosa, Tratado Teológico-Político. 4. ed. Lisboa: Imprensa Nacional.

CHAUÍ, Marilena. 2001. Espinosa: uma filosofia da liberdade. São Paulo: Editora Moderna.

ESPINOSA, Baruch de. [1677] 2011. Tratado Político. Tradução, introdução e notas de Diogo Pires Aurélio. Lisboa: Círculo de Leitores e Temas e Debates. . Tratado Teológico-Político. [1670] 2019. 4. ed. Tradução, introdução e notas de Diogo Pires Aurélio. Lisboa: Imprensa Nacional.

GUERREIRO, Clayton \& ALMEIDA, Ronaldo de. 2021. "Negacionismo Religioso: Bolsonaro e lideranças evangélicas na pandemia Covid 19". Religião \& Sociedade, v. 41, n. 2:4974, maio/ago.

QUIJANO, Aníbal. 2014. Cuestiones y Horizontes: antologia essencial; de la dependência histórico-estructural a lacolonialidad/descolonialidad del poder. Seleção e prólogo de Danilo Assis Clímaco. Buenos Aires: CLACSO.
REIS, Lívia. 2021. "O Brasil não elegeu Bolsonaro porque se tornou mais evangélico". Nexo. https://pp.nexojornal. com.br/opiniao/2021/O-Brasil-n\%C3\%A3o-elegeu-Bolsonaro-porque-se-tornou-mais-evang $\% \mathrm{C}$ 3\%A9lico? fbclid = IwAR04 mHYBu tkgoEdYGiicVfgik0S36LawIB-jdLeOq2d5sfu-86-woBsnw3Q. Acesso em 21/10/2021.

VELHO, Otávio. 2007. "O cativeiro da Besta-Fera". In:__, Mais Realistas do que o Rei: ocidentalismo, religião e modernidades alternativas. Rio de Janeiro: Topbooks. pp. 103-33. . 2017a. "A antropologia e a guerra: não só de narrativas". In: Amir Geiger (org.), Antinomias do Real. Rio de Janeiro: Editora UFRJ. pp. 421-30. . 2017b. "O que nos une". In: Amir Geiger(org.), Antinomias do Real. Rio de Janeiro: Editora UFRJ. pp. 265-78. . 2019. "Roteiro de Busca: sobre a contemporaneidade de Karl Mannheim". Tensões Mundiais, v. 15, n. 29: 17-44,jul./dez. . 2020. "Razão e imaginação para todos os tempos". Tensões Mundiais, v. 16, n. 32: 17-46, set./dez. 